\title{
The Breast Cancer Guideline of the German Gynecological Oncology Working Group (AGO) - History and Current Status
}

\author{
Gunter von Minckwitz for the AGO Breast Commission \\ GBG Forschungs GmbH, Neu-Isenburg / Frankfurt/M., Germany
}

In the year 2001 the Breast Commission of the German Gynecological Oncology Working Group (Arbeitsgemeinschaft Gynäkologische Onkologie, AGO) started to develop recommendations for the diagnosis and treatment of patients with breast cancer. As at that time the German Cancer Society (Deutsche Krebsgesellschaft, DKG) was planning to prepare an S-3 level breast cancer guideline for Germany, the AGO wanted to summarize current common procedures in clinical institutions specialized in gynecological oncology. In Germany the majority of women suffering from breast cancer are traditionally treated in gynecological institutions.

The Commission was aware of the prerequisites of medical guidelines: they have to be clear and concrete, include only evidence based recommendations, and should not ask for significant changes in routines of patients care. But there were also potential pitfalls to be aware of, mainly that guidelines are not being followed if they are not known, if they are out of date, and if they are too restrictive for maintaining the autonomy of physicians.

Individualized therapy has a long tradition in Germany, especially in cancer treatment. Until now, the individual is considered more important than the community. However, this attitude, which in itself has convincing advantages, was wrought up. A physician could prescribe any kind of treatment, based on the argument that the individual situation of the patient made it necessary. In the Anglo-American literature evidencebased medicine was much more developed, leading to the attitude that the community is more important than the individual. It could also be demonstrated that individualized treatment is much more expensive, does not lead to a better quality of life, but does result in inferior overall efficacy of treatment, when compared with guideline-driven treatment plans.

The goal for a German guideline was therefore set: it should provide and be considered as a framework, summarizing all medical procedures with available evidence, but should not be biased by policies favored by individual physicians. By following the guideline, doctors should be ascertained that their action is supported by the medical community; whereas for procedures outside of this framework specific reasons should be given, explained to the patient and meticulously documented. The guideline should be considered as a measure of support and not as a legally obliging directive.

To cover the other prerequisites the idea to prepare a set of slides was born. The content of a slide can much easier be discussed in a group and obtain a consensus. Slides can easily be distributed and used for education, and mistakes or need for improvement will be discovered when they are presented during educational sessions and discussed within the medical community.

As a start 15 distinct topics of primary and metastatic breast cancer were identified. One or two members of the commission were engaged to one topic and were asked to prepare 5 slides covering the most important current issues related to this topic. All slides were then presented to the group for discussion and thereafter each statement was agreed on by a democratic vote. However, the group immediately became aware that this first version of slides had to be improved and updated as soon as possible. So the decision was taken to meet annually and to revise the slide set.

During the next 4 annual reviews several improvements have been made:

- Level of evidence and grade of recommendations for each guideline have been assessed by systematic literature research and are now provided.

- A new, more practical recommendation system was developed by the commission (table 1).

- A bibliography of the most important references was provided.

\begin{tabular}{ll}
\hline KARGER & ๑ 2006 S. Karger GmbH, Freiburg \\
Fax +49 761 4520714 & Accessible online at: \\
$\begin{array}{l}\text { E-mail Information@Karger.de } \\
\text { www.karger.com }\end{array}$ & www.karger.com/brc
\end{tabular}


Table 1. Definition of the grade of recommendation by the Breast Commission

\begin{tabular}{ll}
\hline Recommendation & Definition \\
\hline++ & $\begin{array}{l}\text { examination or therapeutic intervention is highly beneficial for the patient, can be recommended without any restrictions } \\
\text { and should be carried out }\end{array}$ \\
+ & $\begin{array}{l}\text { examination or therapeutic intervention is of restricted benefit for the patient and can be carried out } \\
\text { examination or therapeutic intervention has not shown any benefit so far and may be carried out in single cases; based on } \\
\text { existing data, no explicit recommendation can be given }\end{array}$ \\
- & $\begin{array}{l}\text { examination or therapeutic intervention may be detrimental to the patient and should therefore not be carried out } \\
\text { examination or therapeutic intervention is detrimental to the patient and should by no means be carried out }\end{array}$ \\
\hline- &
\end{tabular}

- Experts from other disciplines were invited to participate (medical oncology, radiotherapy, breast diagnostics, pathology).

- New topics especially for rare indications were included (e.g. breast cancer in pregnancy, in young and old patients, in male patients).

- Potential conflicts of interests were collected from each member.

- Topics were switched to other members by rotation to avoid blindness to mistakes.

The guidelines have been presented to a broad audience every 2 years on a state-of-the-art meeting; they have been published in books with a print of each slide or in full text, as well as in a condensed version in several journals. The slide set is being used on almost every educational event which relates to breast cancer in Germany. Only recently a version in English was prepared and is available in the internet (www.ago-online.de), and, as there is currently no guideline for metastatic breast cancer available in the literature, a publication is under review in a European journal.

This publicity has raised the impact of these guidelines. They became the backbone of the S3-level guideline of the German Cancer Society published in 2004 after 2.5 years of preparation. The complex procedure of reaching a consensus had specific impact on the content of this more political piece of work. The statements are kept very broad and unspecific, so that they will not loose their validity to early and that health care providers could not exclude specific procedures from reimbursement. So, both guidelines have distinct political and practical tasks and aims.

The increasing importance of the guideline also attracted the interest of the pharmaceutical industry as well as of health care providers. There have been, on some occasions, attempts

\section{Members of the Breast Commission 2006}

Ingo Bauerfeind, München

Joachim Bischoff, Magdeburg

Jens Uwe Blohmer, Berlin

Klaus Brunnert, Osnabrück

Serban D. Costa, Magdeburg

Peter Dall, Lüneburg

Ingo J. Diel, Mannheim

Nikos Fersis, Heidelberg

Michael Friedrich, Lübeck
Kay Friedrichs, Hamburg Bernd Gerber, Rostock

Uwe-Jochen Göhring, Bonn

Volker Hanf, Fürth

Nadia Harbeck, München

Jens Huober, Tübingen

Christian Jackisch, Offenbach

Wolfgang Janni, München

Manfred Kaufmann, Frankfurt

to influence the content of a recommendation. However, the commission was able to keep its independence and this was finally respected on all sides.

Currently, the tasks of the AGO breast cancer guideline can be summarized as follows:

- To provide clear and practical recommendations for the routine care in frequent as well as in infrequent clinical situations,

- to avoid over-treatment as well as under-treatment,

- to maintain a stringent care of breast cancer patients without contradictory advice from different physicians involved in their treatment,

- to provide the standard operating procedure that is mandatory for breast centers,

- to identify research questions and to help in choosing standard treatments in randomized controlled trials,

- to standardize the content for education of students and fellows,

- to provide recommendations for 'off-label' use of pharmaceutical compounds in specific disease situations where randomized trials and a registration cannot be realized, and

- to save costs by avoiding ineffective procedures and to support effective treatments with their positive impact on longterm cost-effectiveness.

In this issue of Breast Care you will find brief summaries of the most important presentations given at the last AGO Stateof-the-Art Meeting in May 2006 in Gravenbruch near Frankfurt, where the 2006 version of the AGO guideline was introduced to the public (all presentations can be downloaded at www.ago-online.de).

The commission hopes that these will help the readers to further improve the health care provided to their breast cancer patients.

Nicolai Maass, Kiel

Volker Möbus, Frankfurt

Ulrike Nitz, Düsseldorf

Carsten Oberhoff, Essen

Mahdi Rezai, Düsseldorf

Gerhard Schaller, Berlin

Anton Scharl, Amberg

Rita Schmutzler, Köln

Andreas Schneeweiß

Heidelberg (AIO)

Ingrid Schreer, Kiel (Radiodiagnostik)
Peter Sinn, Heidelberg (Pathologie)

Erich F. Solomayer, Tübingen

Rainer Souchon, Hagen (ARO)

Elmar Stickeler, Freiburg

Christoph Thomssen, Halle

Michael Untch, Berlin

Gunter von Minckwitz, Neu-Isenburg/

Frankfurt 